\title{
Effect of Clay Additives in the Control of Temperature and Relative Humidity inside an Adobe Room
}

\author{
${ }^{1}$ Hamza B And ${ }^{2}$ Abdullahi S. \\ ${ }^{1,2}$ Department of Physics \\ Usmanu Danfodiyo University
}

Sokoto,

Nigeria

\begin{abstract}
Adobe buildings have been in used over a long period of time in many parts of the world, more especially in the African continent. It has been used to satisfy the shelter need for human comfort, animals comfort and preservation of food crops that are very important for human lives. To prevent the heat from the sun radiation to have a severer effect on the items, Adobe building was used for its ability to control temperature and humidity fluctuations within the building. In this work, two rooms were constructed one with adobe and the other with an additives material to the adobe. A study on the thermal performance of the two rooms was carried out to compare the inside rooms temperature and relative humidity. It was found that the average differences in the inside temperature and relative humidity were -2 degrees and +1 percent respectively, which shows that averagely the temperature of the improved room is lower than that of the control room while the converse is the case for the relative humidity.
\end{abstract}

Key word: Solar radiation, Thermal, Temperature, Relative humidity and Adobe.

\subsection{INTRODUCTION}

The adobe house construction is very common in many areas of the world. In USA it is developed by the Indians in the southwest regions. In Africa, adobe house construction is seen in the north and central part of Nigeria, in the southern part of the country, traditional houses also have walls made of stones and adobe. It is well known that adobe house construction yield a natural air conditioning effect, the rooms are cool at midday and warm at night. The house constructions above are nothing but passive solar buildings.

For passive solar buildings, heating the building is possible via direct heat gain and /or thermal storage methods and there have been many researches on this area (Bal comb, 1992., Givoni, 1991, Carter \& DeWilliers, 1987.). Although direct heat gain method is simple and inexpensive, it suffers from large temperature swings besides strong directional day lighting (Athienitis, Sullivan, \& Holland ., 1986). In addition, direct heat gain method can be effected very fast from outside temperature fluctuations which results to a bed discomfort level for indoors (Maloney, Wan, Chen, \& Thorp, 1982; Sodha, Nayak, Bansal, \& Goyal, 1982; and Athanassouli, 1988). For thermal storage buildings on the other hand, walls and floors, are used as heat storage elements, and stored energy in the walls and floors during day period can be used for heating during nights.

Kanshik, et al. (1982), investigated the thermal behavior of a non-air conditioned building with walls/roofs exposed to periodic solar radiation and air atmosphere. The inside air temperature in the room was controlled by an isothermal mass, windows and door in the walls of the room. The effects of air ventilation and infiltration, the heat capacities of the isothermal storage mass, inside air, walls/roof, and heat loss into the ground were studied. After using numerical computer model, it was found that the effects of the heat capacity of the isothermal mass and the basement ground was to reduce the inside air temperature- swing. The presence of a window was found to increase the inside air temperature even when the window area was made much smaller than the wall/roof area.

Other authors Alford et al. (2000), investigated the periodic heat transfer in walls/roof of buildings maintained at constant indoor air temperature. He reported that for a non-air-conditioned building the inside air temperature is variable and controlled by many factors like air ventilation and infiltration, location and size of windows, furnishings basement/ground heat conduction etc. 
The climatic situation of Sokoto hot and dry coupled with the poverty level of the inhabitants of the area, removed all possibility of using the modern devices (such as electric humidifier and electric fan) in all areas to improve the microclimate of room or store (which depend on the intense radiation from the sun, ground and surrounding buildings).

Accordingly, the study of indoor condition of an adobe room is of fundamental importance from the point of views of basic economics and for its application to storage Maduekwe et al. (2002),

Adobe is cheap and abundant within the area, in-fact, most of the houses are made from adobe, Therefore it can be use to design a good room for human habitat or store for food crops. An important feature of the Adobe house is that it has the ability to attenuate the heat waves that is transferred through it and the fluctuations of the temperature inside the store could be control Algifri et al. (1992),

In this work the temperature and relative humidities for the two rooms were studied.

\subsection{EXPERIMENTAL DETAILS}

Two rooms were constructed at Sokoto Energy Research Centre, Usmanu Danfodiyo University, Sokoto-Nigeria.

Room 1 was constructed with control bricks (clay with no additives) only, while room 2 was made from the improved brick (clay enriched with additives of $20 \%$ Neem Leaves and $10 \%$ Rice Husk).

For either of the two rooms, the dimension of each of the walls (North, West, South and East) as well as the roof is $2000 \mathrm{~mm} \times 2000 \mathrm{~mm}$ in area. The West, South and East walls contain two windows / ventilation (one at the top and one at the bottom), each of $200 \mathrm{~mm} \times 200 \mathrm{~mm}$ in area. The North wall contained one similar window at the top and a door of area $300 \mathrm{~mm} \times$ $400 \mathrm{~mm}$ at the bottom.

Each of the rooms was having the dimensions shown in Figure 1 below.

$S(t)$
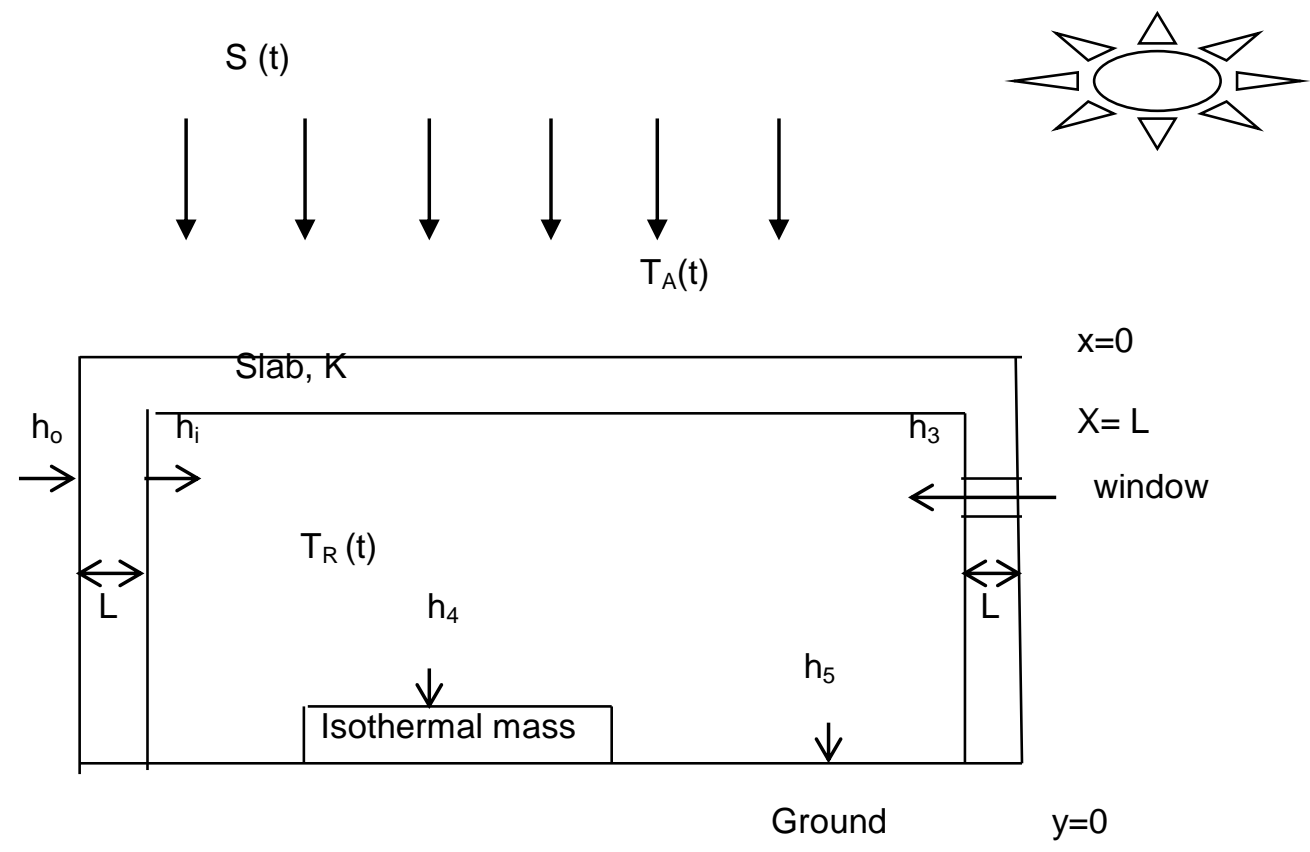

Figure 1: Illustration of a sketched adobe room (Hamza 2016).

\subsection{RESULTS AND DISCUSSION}

The rooms were analyzed based on thermal performance over the month of May 2009 data. The analysis was done on a complete month input data's from the Sokoto Energy Research Centre, Sokoto - Nigeria.

Indoor and outdoor parameters were measured for the two rooms on half hour interval, using hygrometer, thermocouplethermometer and data logger, that logged the ambient temperature, outside room humidity, solar radiation, and wind speed.

The readings from the instruments were for the following parameters:
(a) Relative humidity inside the rooms.
(b) Wind speed outside the rooms.
(c) Ambient temperature.
(d) Global horizontal radiation.

(e) Inside room temperatures 
The readings were used in plotting the graphs Figure 2 to Figure 7.

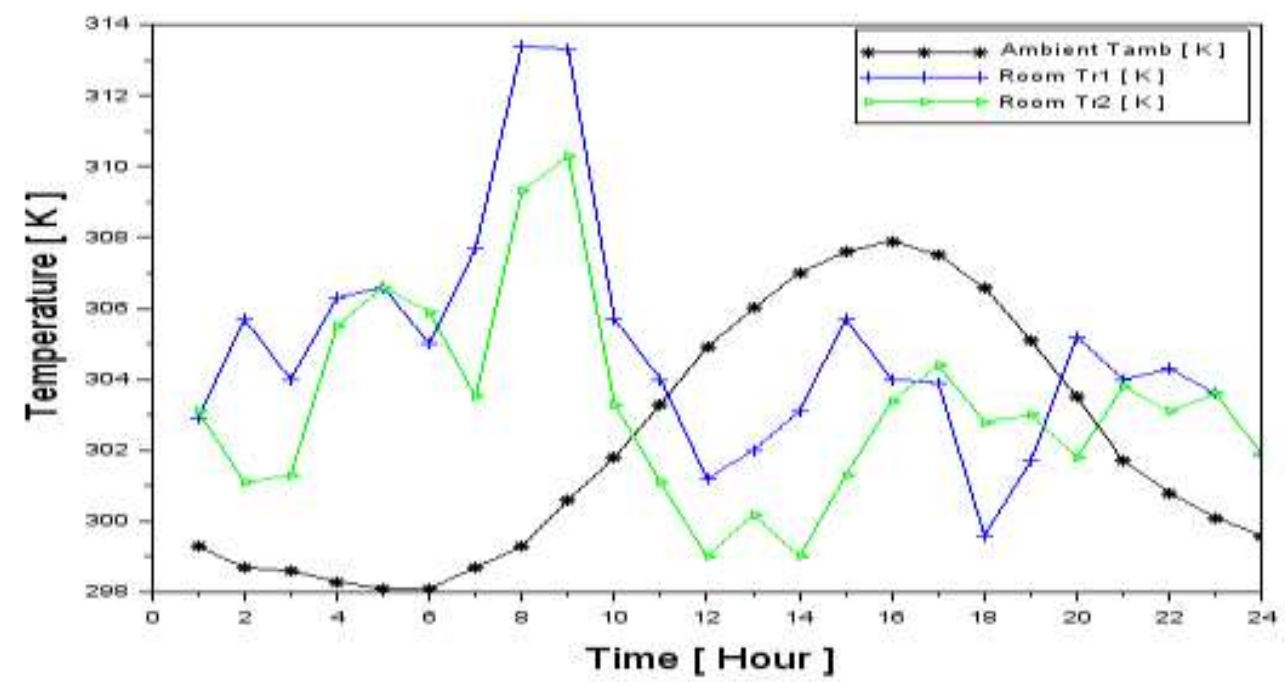

Figure 2: Graph of Monthly Hourly Average Ambient, Room 1 and Room 2, Temperature (K) against Time of the day (hour)

Figure 2, indicates that the ambient temperature was lower than room 1(control) and room 2 (improved) temperatures between the early morning hours of 1:00am to 10:00am and between night hours of 21:00pm to 24:00pm, while on the other hand converse is the case during the remaining hours of the day (11:00noon to 20:00pm), this may not be unconnected with the insulating properties of the clay walls and roof of the rooms. Also the inside room temperature of the control room 1 was almost always greater than that of the improved room 2, which may not be unconnected with the change in the thermo-physical properties of the building brick due to addition of the organics in to the clay. Specifically there is an average of 2 degree of temperature deference between the control room and the improved room and this is a very significant achievement. The figure shows that the inside room temperature for both rooms is higher than the ambient temperature at night and since heat flows from the higher temperature region to lower temperature region, heat will flow from the inside to the outside until the inside temperature equals that of the outside. During the day, due to the sun's radiant heat, the outside temperature becomes hotter than the inside and therefore the direction of heat flow is reversed. This is similar to what was observed by Fapetu and Ogedengbe (2004).

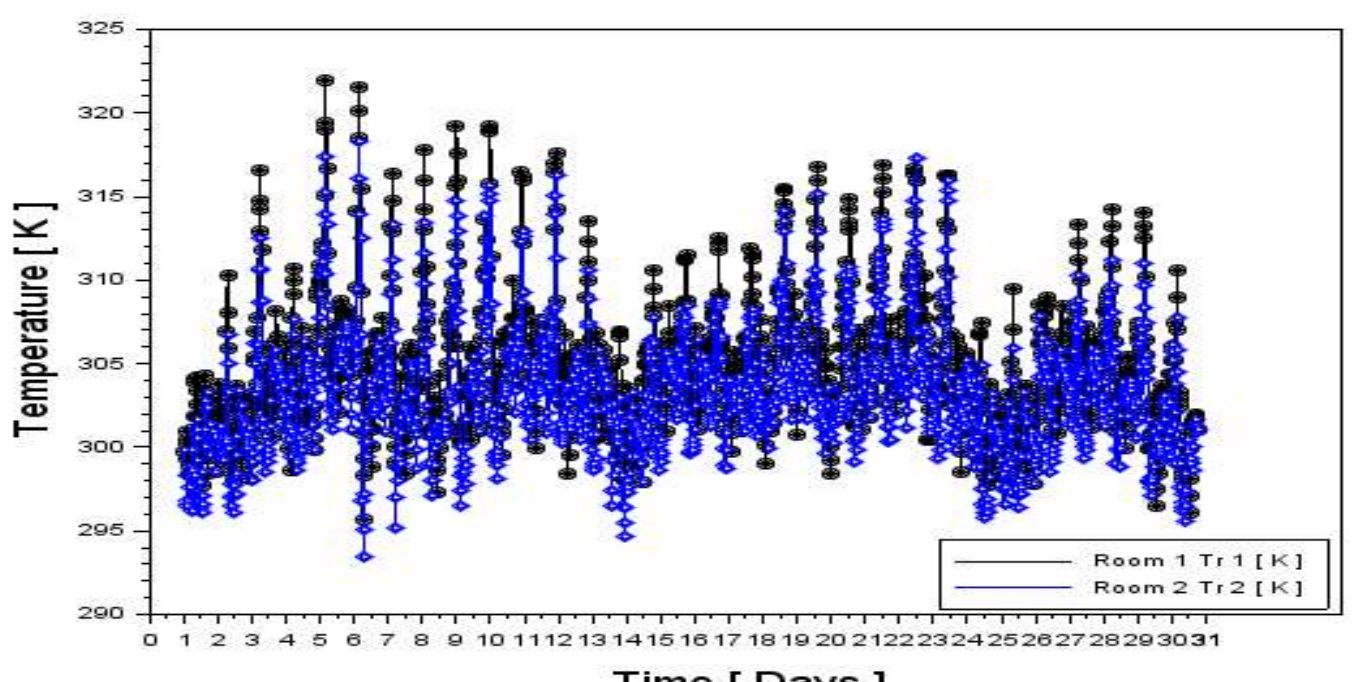

Time [ Days ]

Figure 3: Graph of Room 1 and Room 2, Temperature (K) against Time (Day)

Figure 3, shows the monthly hourly average temperature $(\mathrm{K})$ for the inside room 1 and inside room 2 with its variation with time of the day (hour). The graphs indicated that the temperature inside room 2 is almost always lower than that in room 1(control) and this could be due to the insulating effect of the clay additives put into the clay during moulding process. The temperatures of the rooms are higher than the ambient temperature in the morning hours between 1.00am to 10.00am same thing between $21.00 \mathrm{pm}$ to $24.00 \mathrm{pm}$. However the room's temperatures are lower than the ambient temperatures during the hot periods of the day (i.e between $11.00 \mathrm{am}$ to $20.00 \mathrm{pm}$ ). 


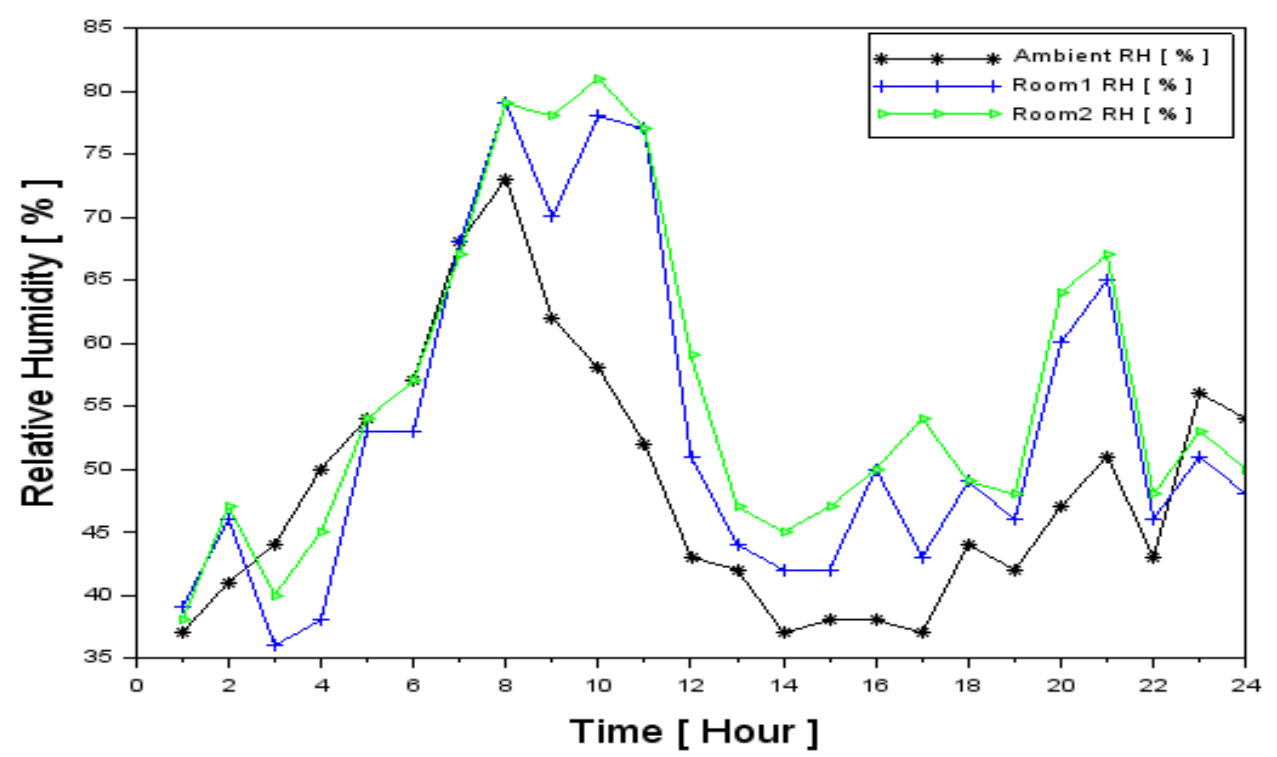

Figure 4: Graph of Monthly Hourly Average Ambient, Room 1 and Room 2, Relative Humidity RH (\%) against Time of the day (hour)

Figure 4, shows the monthly hourly average ambient, inside room 1 and inside room 2 relative humidity (\%) with its variation with time of the day (hour). The graphs indicated that the ambient relative humidity was lower than room 1 and room 2 except in the early morning hours and late night hours of 03:00am to 07:00am and 23:00pm to 24:00pm respectively. This may not be unconnected with the insulating properties of the clay walls and roof of the rooms. Also the inside room relative humidity of the simple clay brick room 1 was almost always lower than that of the improved clay brick room 2 , which may not be unconnected with the change in the thermo-physical properties of the building clay brick. This is similar with the observation by Al-Homoud (2005) that the thermal performance of building envelope is determined by the thermal properties of the materials used in its construction (brick with or without additives).

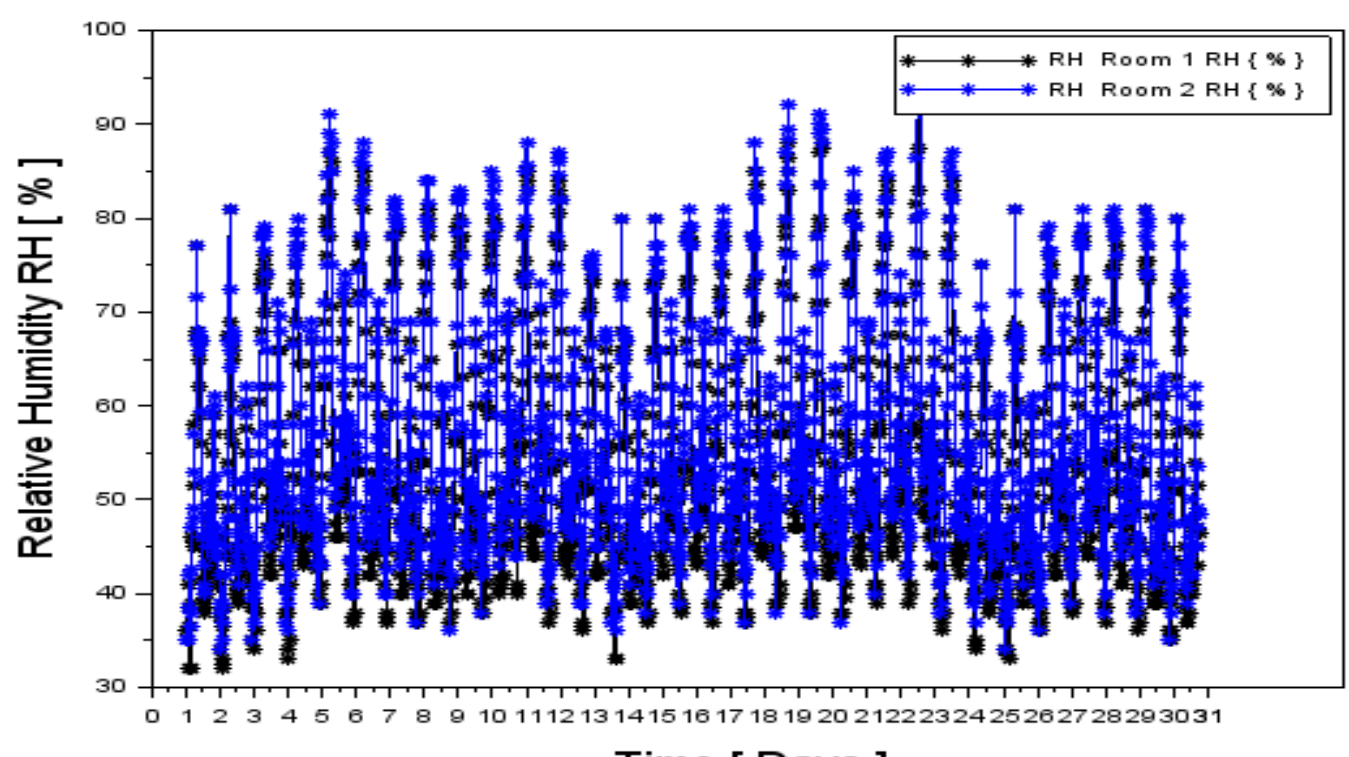

Time [ Days ]

Figure 5: Graph of Room 1 and Room 2, Relative Humidity (\%) against Time (Day)

Figure 5 is a graph of inside rooms (1 and 2) daily relative humidity against time (day) for the month of May 2009. The graph indicates that the relative humidity in room 2 is mostly higher than that of room 1 this is expected as room 2 is cooler than room 1 , for as the cooler the air in the room the higher the relative humidity. 


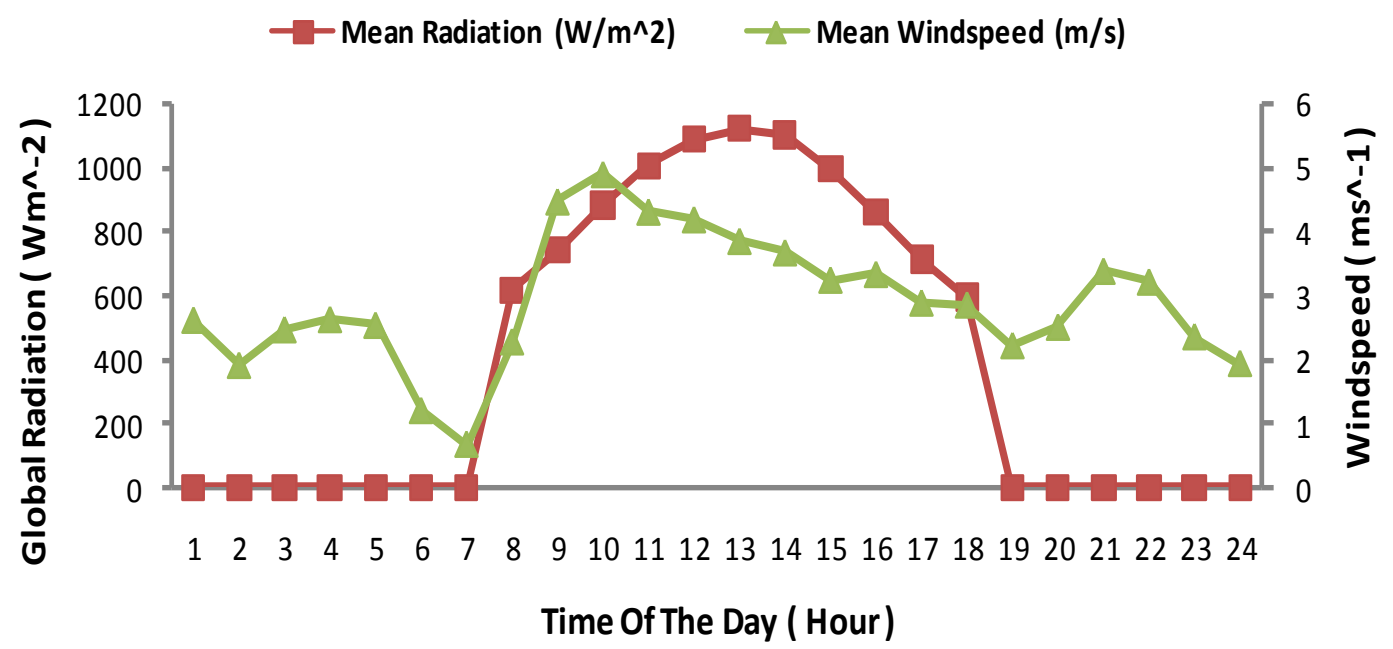

\section{Figure 6: Graph of average hourly global horizontal radiation $\left(\mathrm{Wm}^{-2}\right)$ and average hourly wind speed ( $\mathrm{m} / \mathrm{s}$ ) against time of the day (hour)}

Figure 6 shows the monthly hourly average global horizontal radiation $\left(\mathrm{Wm}^{-2}\right)$ against time of the day (hour). The radiation was zero between the hours of $1.00 \mathrm{am}$ to $7.00 \mathrm{am}$ and between $19.00 \mathrm{pm}$ to $24.00 \mathrm{pm}$. It has a peak value of $1100 \mathrm{Wm}^{-2}$ at 13.00 noon. The radiation makes a parabolic curve between the hours of $7.00 \mathrm{am}$ to $19.00 \mathrm{pm}$, with a peak value of $1100 \mathrm{Wm}^{-2}$ which was at 13.00 noon. Due to intense solar radiation, the ground and the surroundings are heated up very quickly during day time (Nayak \& Prajapati, 2006).

Figure 6 also shows the variation of monthly hourly average wind speed $(\mathrm{m} / \mathrm{s})$ with time of the day (hours). It was observed that the wind speed keep fluctuating throughout the day, having a peak value of $5 \mathrm{~ms}-1$ at $10.00 \mathrm{am}$. And the lowest observed monthly average wind speed was $1 \mathrm{~ms}-1$ and this was at 7.00am. Hot winds blow during the day and sand storms are also experienced. The night is usually cool and pleasant. A generally clear sky, with high solar radiation causing an uncomfortable glare, is typical of the area. As the sky is clear at night, the heat absorbed by the ground and surrounding objects during the day is quickly dissipated to the atmosphere. Hence, the air is much cooler at night than during the day (Nayak \& Prajapati, 2006).

In such a climate, it is imperative to control solar radiation and movement of hot winds. The design criteria should therefore aim at resisting heat gain by providing shading, reducing exposed area, controlling and scheduling ventilation, and increasing thermal capacity (Nayak \& Prajapati, 2006).

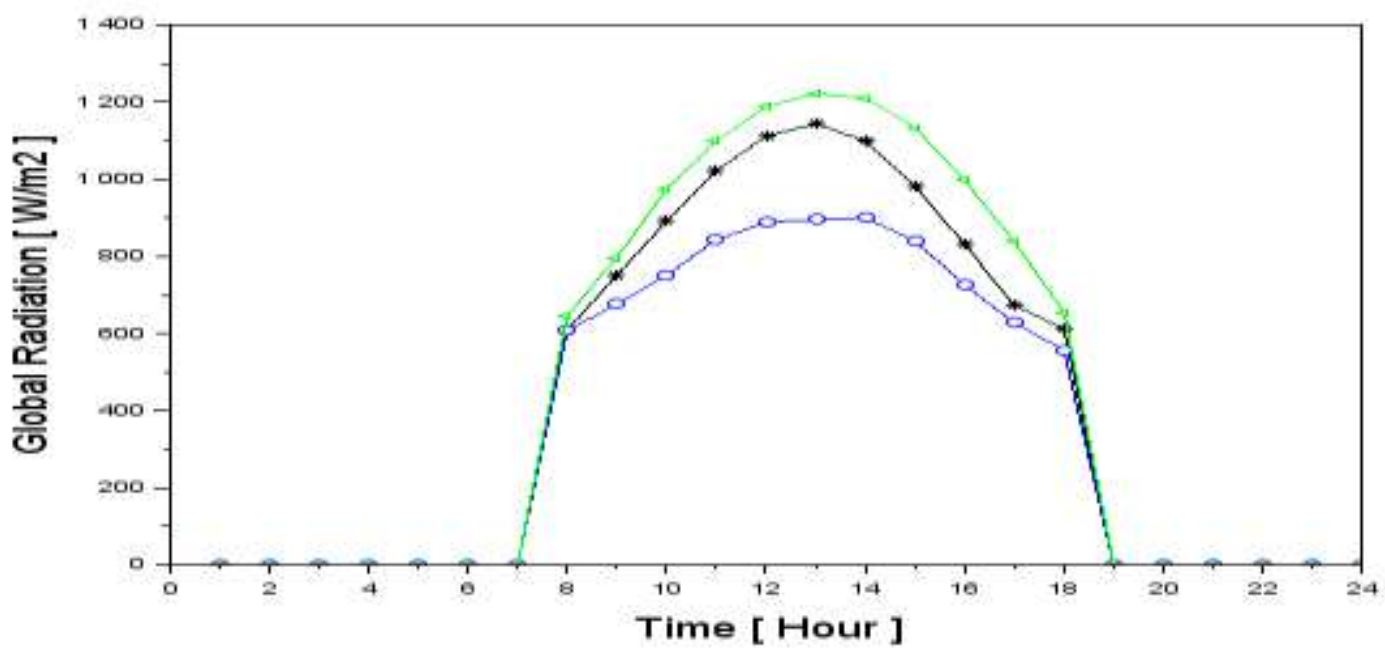

Figure 7: Graph of monthly hourly average global horizontal radiation $\left(\mathrm{Wm}^{-2}\right)$ against time of the day (Hour)

Figure 7 shows a graph of monthly hourly average global radiation $\left(\mathrm{Wm}^{-2}\right)$ against time of the day (Hour). These are for the days with maximum, mean, and minimum global radiation, (11th, 12th and 31st May, 2009 respectively). All these radiations are having their pick values at 12: $30 \mathrm{pm}$. 
International Journal of Advances in Scientific Research and Engineering (ijasre),Vol 5 (7), July-2019

\subsection{CONCLUSION}

The research was done to assess the potential of local clay building (adobe) as comfortable building, in particular as a cheap and good environment for human havitat and the storage of food crops. Effect of local additives on the heat transfer processes across the adobe walls was examined. The results of addition of additive to the clay used in the construction of improved room has lowered the inside room temperature by about 2 degrees it has also increase the relative humidity by 1 percent.

\section{REFERENCES}

1. Alford, J. S., Ryan, L. and Urban, F.O. Effect of heat storage and variation in outdoor temperature and solar intensity on heat transfer through wall. Solar Energy, 4, 2000, 392-397.

2. Algifri, A. H., Bingadhi, S. M. and Nijaguna, B. T. Thermal behaviour of Adobe and concrete house in Yemen. Renewable Energy, 2, 1992, 597-602.

3. Athanassouli, G. (1988). A model to the thermal transient state of an opaque wall due to solar radiation absorption. Solar Energy, 41(81), 71-80.

4. Athienitis, A. K., Sullivan, H. F., \& Holland, K. G. T. (1986). Analytical model, sensitivity analysis, and algorithm for temperature swings in direct gain rooms. Solar Energy, 36(4), 303-312.

5. Balcomb, J. D., (1992). Passive solar buildings. Cambridge, MA, Press.

6. Carter, C., \& DeWilliers, J. (1987). Principles of passive solar buildings design. New York, Pergamon.

7. Fapetu, D. P., \& Ogedengbe, T. I. (2004). An assessment of temperature variation in building types in Nigeria : Akure as a case study. West Indian Journal of Engineering, 27(1), 18-27.

8. Givoni, B. (1991). Characteristics, design implications, and applicability of passive solarheating systems for buildings. Solar Energy, 47(6), 425-435.

9. Hamza, B. S. (2016). Modeling The Thermal Load Of An Adobe Room For The Storage Of Onions A Thesis Submitted To The Postgraduate School Usmanu Danfodiyo University, Sokoto, Nigeria, In Fulfillment Of The Requirement For The Award Of Degree Of Doctor Of Philosophy In Physics.

10. Kanshik, S. C., Sodha, M. S. Bansal, P.K and Bhardwaj, S. C. (1982). Solar Thermal modeling of a non- air conditioned building: evaluation of overall heat flux.International Journal of energy research. 143 - 155.

11. Maduekwe, A. L., Balogun, W and Garba, B. (2002,). Controlling the periodic flux of solar radiation in to an Adobe room using slab and foam roof combination. Nigerian Journal Of Renewable Energy. 10, 108-116.

12. Maloney, J., Wan T., Chen, B., \& Thorp, J. (1982). Thermal network predictions of the daily temperature fluctuations in a direct gain room. Solar Energy, 29(3), 207-223.

13. Nayak, J. K and Prajapati, J. A. (2006), Handbook of energy conscious buildings, Hall, New Jersey.

14. Sodha, M. S., Nayak, J. K., Bansal, N. K., \& Goyal, I. C. (1982). Thermal performance of a solarium with removable insulation. Building and Environment, 17(1), 23-32. 